\title{
Uremic Tumoral Calcinosis Resolved by Improvements in Hyperphosphatemia
}

\author{
Hirofumi Watanabe ${ }^{1}$, Ryo Koda ${ }^{1}$, Noriaki Iino ${ }^{1}$ and Ichiei Narita ${ }^{2}$ \\ Key words: calcification, chronic kidney disease, dialysis, hyperphosphatemia, tumoral calcinosis
}

(Intern Med 56: 1605-1606, 2017)

(DOI: 10.2169/internalmedicine.56.8145)

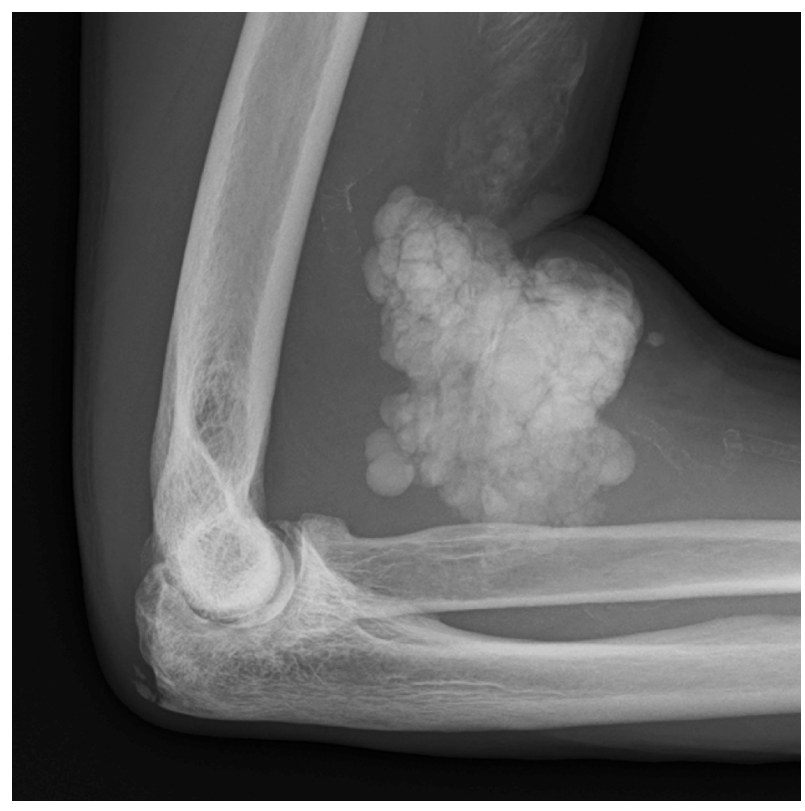

Picture 1.

A 62-year-old man receiving hemodialysis due to diabetic nephropathy for 10 years presented with subcutaneous nodules on his right elbow (noticed 1 year prior, enlarged, and accompanied with pain). X-ray revealed multiple lobulated calcifications (Picture 1). Similar smaller masses were observed on his left elbow and both first metacarpophalangeal joints. Although multiple non-calcium-based phosphate binders and cinacalcet were formulated, significantly elevated phosphorus levels $(13.4 \mathrm{mg} / \mathrm{dL})$ were observed with normal calcium levels $(9.1 \mathrm{mg} / \mathrm{dL})$ and mild hyperparathyroidism (intact parathyroid hormone, $150 \mathrm{pg} / \mathrm{mL}$ ). After six months, he was admitted for buttocks pyoderma, and his drug compliance and diet therapy improved. Three months later, his phosphorus levels were reduced $(3.6 \mathrm{mg} / \mathrm{dL})$, with calcium

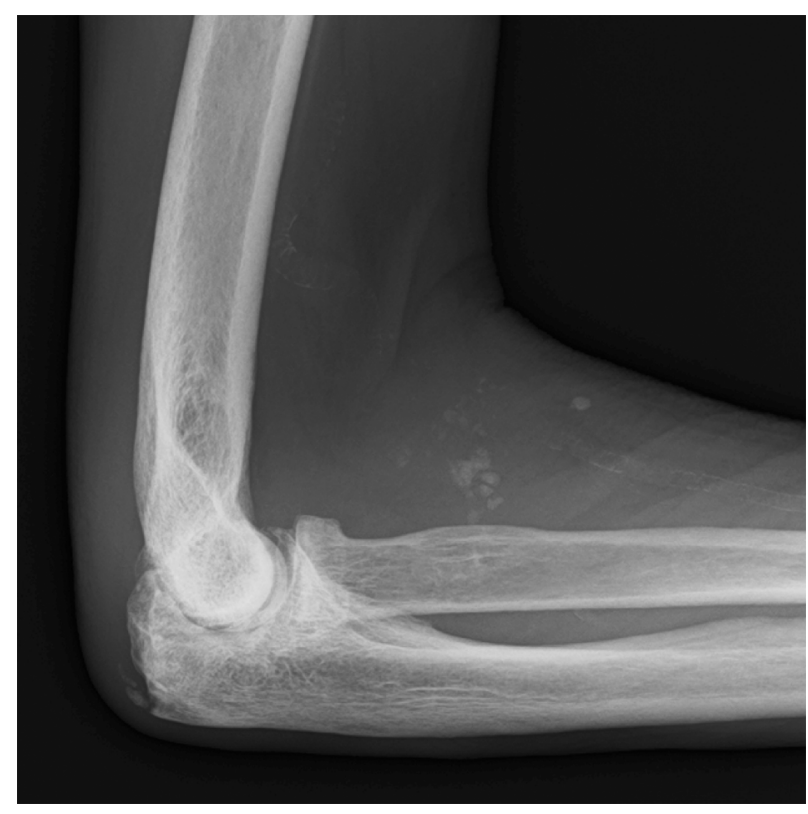

Picture 2.

$9.7 \mathrm{mg} / \mathrm{dL}$, intact parathyroid hormone $31 \mathrm{mg} / \mathrm{dL}$, and a remarkable reduction in calcifications (Picture 2). Uremic tumoral calcinosis occurs with marked phosphorus elevation (1). It is difficult to treat, and several treatments, such as sodium thiosulphate, have been proposed (2). However, this case was resolved only by improving his hyperphosphatemia.

The authors state that they have no Conflict of Interest (COI).

\section{References}

1. Alfrey AC. The role of abnormal phosphorus metabolism in the progression of chronic kidney disease and metastatic calcification.

\footnotetext{
${ }^{1}$ Department of Nephrology, Uonuma Institute of Community Medicine, Niigata University Medical and Dental Hospital, Japan and ${ }^{2}$ Division of Clinical Nephrology and Rheumatology, Niigata University Graduate School of Medical and Dental Sciences, Japan Received for publication August 19, 2016; Accepted for publication October 17, 2016 Correspondence to Dr. Hirofumi Watanabe,watanabeh@med.niigata-u.ac.jp
} 
Intern Med 56: 1605-1606, 2017 DOI: 10.2169/internalmedicine.56.8145

Kidney Int Suppl 66: S13-S17, 2004.

2. Malbos S, Urena-Torres P, Cohen-Solal M, et al. Sodium thiosulphate treatment of uraemic tumoral calcinosis. Rheumatology (Oxford) 53: 547-551, 2014.
The Internal Medicine is an Open Access article distributed under the Creative Commons Attribution-NonCommercial-NoDerivatives 4.0 International License. To view the details of this license, please visit (https://creativecommons.org/licenses/ by-nc-nd/4.0/).

(C) 2017 The Japanese Society of Internal Medicine http://www.naika.or.jp/imonline/index.html 